\title{
Post-operative abdominal adhesions-awareness of UK gynaecologists - a survey of members of the Royal College of Obstetricians and Gynaecologists
}

\author{
Geoffrey Trew • Ian Cooke • Adrian Lower • \\ Enda McVeigh
}

Received: 26 February 2008 / Accepted: 13 May 2008 /Published online: 24 June 2008

(C) Springer-Verlag 2008

\begin{abstract}
With the recent publication of the European Society of Gynaecological Endoscopy consensus position on adhesion reduction, all members of the Royal College of Obstetricians and Gynaecologists were sent a postal survey with the aim to understand and benchmark UK gynaecological surgeons' attitudes and actions on adhesions. As expected, of the 356 who responded, gynaecological surgeons $(72 \%)$ were the majority. Over $85 \%$ of respondents agreed that adhesions develop after any type of gynaecological surgery, and more than $50 \%$ considered adhesions were now the most common complication of abdominal surgery. Approximately four out of five respondents agreed that all gynaecological patients should be informed of the risk of adhesions and $61 \%$ noted that they
\end{abstract}

G. Trew $(\bowtie)$

Hammersmith and Queen Charlotte's Hospital,

3rd Floor, Ham House Room 3.15, Du Cane Road,

London W12 0HS, UK

e-mail: g.trew@ic.ac.uk

G. Trew

Imperial College, University of London,

London, UK

I. Cooke

University of Sheffield,

Sheffield, UK

A. Lower

The London Clinic,

London, UK

E. McVeigh

Nuffield Department of Obstetrics and Gynaecology, University of Oxford, John Radcliffe Hospital,

Oxford, UK routinely inform patients for all or some procedures. However, written information was only provided by $2.3 \%$ of respondents. Importantly, respondents agreed that a routine adhesion reduction strategy with good surgical technique was fundamental. Respondents' use of specific agents was identified with $78.8 \%$ relying on surgical technique as their current strategy. While $78.8 \%$ would use an anti-adhesion agent in high-risk surgery—only $6.1 \%$ would consider use in all surgery. Most surgeons still rely on surgical technique alone as their anti-adhesion strategy despite increasing evidence of the important potential additional benefits of using anti-adhesion agents.

Keywords Adhesions · Gynaecology · Surgery · Survey

\section{Introduction}

Evidence of the extent of the problems of post-operative adhesions has been mounting in recent years, yet adhesiolysis remains the main treatment despite the fact that adhesions reform in most patients [1]. Developments in adhesion reduction strategies and new agents now offer a realistic possibility of reducing the risk of adhesions forming and can improve the outcomes for patients and the associated onward burden for patients, surgeons and healthcare systems. Recognising this, consensus positions were published in the UK and Germany in 2004 following a series of meetings to review the available evidence $[2,3]$. Most recently, a major European project was initiated by the European Society of Gynaecological Endoscopy (ESGE) to assess the evidence for adhesions and adhesion reduction options and a European consensus position on the management of adhesions in routine gynaecological surgery 
has been published $[4,5]$. This highlights that adhesions are the most frequent complication of abdominopelvic surgery, yet many surgeons are still not aware of the extent of the problem and its consequences. Clear proposals on the actions that gynaecologists should now take are presented in the consensus. These include the recommendation to inform patients of the risks associated with adhesionrelated complications during the consent process. With evidence increasing to support the efficacy of adhesion reduction agents to complement good surgical practice, the European consensus proposes that all surgeons should act now to reduce adhesions and fulfil their duty of care to patients $[4,5]$.

In respect of these publications and the extent of evidence of the problem of adhesions, what actions are we, as surgeons, taking to fulfil our duty of care to patients? Are we discussing with them the risk of adhesions that routine surgery poses? Do we know the options available to reduce the risks of adhesions forming? How realistic is it to implement routine adhesion reduction strategies? Do we have a benchmark from which we can go forward in light of the mounting evidence of risk and proposals for action? To answer these and other adhesionrelated questions, we undertook a survey of UK gynaecological surgeons.

\section{Materials and methods}

The survey was performed using a comprehensive but concise four-page questionnaire ("Appendix") which included questions on basic understanding of the implications and burden of adhesions; considerations on risk to patients and a patient's right to be informed; strategies to reduce adhesions - including key steps in surgical practice; and considerations, awareness and use of anti-adhesion agents. The questions were designed to explore the key aspects of the recent European consensus proposals $[4,5]$ to allow the development of a benchmark as to the future impact the proposals may have.
In designing and undertaking the survey, we noted the previous work and findings of earlier adhesion surveys [6] and the recommendations on good practice in the conduct and reporting of survey research [7]. The Royal College of Obstetricians and Gynaecologists (RCOG) Council reviewed the survey questionnaire and confirmed it acceptable for academic research of their members. This was then posted to all RCOG members in May 2007 overprinted with 'Important Gynaecological Adhesion Survey' but no further attractant or incentive was offered and no follow-up of the survey was undertaken as the RCOG Council gave limited access to its membership database. It was also not possible for the RCOG to subcategorise their membership base to allow targeting of surgical gynaecologists alone. We recognised from the outset that a simple postal mailing of all members may not get a high response- healthcare market research experts suggest $5-10 \%$ (personal communication, Gary King, Director GfK HealthCare, GfK NOP Limited). In trying to get a snapshot of current awareness and action in the UK, we considered the survey would however provide an appropriate benchmark which could then allow future audit.

All completed questionnaires received by 10th July 2007 were entered onto a database and analysed anonymously.

\section{Results}

Of the 4,010 survey questionnaires sent to the mailing list provided by the RCOG, 356 were analysed. An additional 34 questionnaires returned were rejected and not analysed either because they were not completed (20) or because the respondents did not operate on patients (14). Most respondents were senior-level surgeons (Table 1).

The majority of respondents agreed (47.1\%) or strongly agreed $(39.0 \%)$ that adhesions develop following any type of gynaecological surgery while almost one in ten $(9.3 \%)$ disagreed and almost one in 20 strongly disagreed (4.7\%). Over $98 \%$ of respondents agreed $(40.3 \%)$ or strongly agreed $(58.8 \%)$ that some procedures carry a higher risk

Table 1 Respondent status and geography

\begin{tabular}{|c|c|c|c|c|c|}
\hline \multicolumn{2}{|l|}{ Speciality } & \multicolumn{2}{|l|}{ Grading } & \multicolumn{2}{|l|}{ Geography (\%) } \\
\hline Gynaecological surgeon & 256 & Consultant & 233 & London and South East & 25 \\
\hline Reproductive surgeon & 21 & Registrar & 81 & North & 22 \\
\hline Gynaecological laparoscopist & 36 & Trainee & 14 & Midlands & 16 \\
\hline Gynaecological oncologist & 11 & Associate specialist-staff grade & 22 & Central and South West & 15 \\
\hline Urogynaecologist & 9 & & & Scotland & 11 \\
\hline 'Other' (general obstetricians and gynaecologist) & 16 & & & Wales & 7 \\
\hline Not recorded & 22 & & & Northern Ireland & 2 \\
\hline & & & & Eire & 2 \\
\hline
\end{tabular}


Fig. 1 a, b Procedural risk of adhesions. a) Open Surgery, b) Laparoscopy

\section{a Open Surgery}

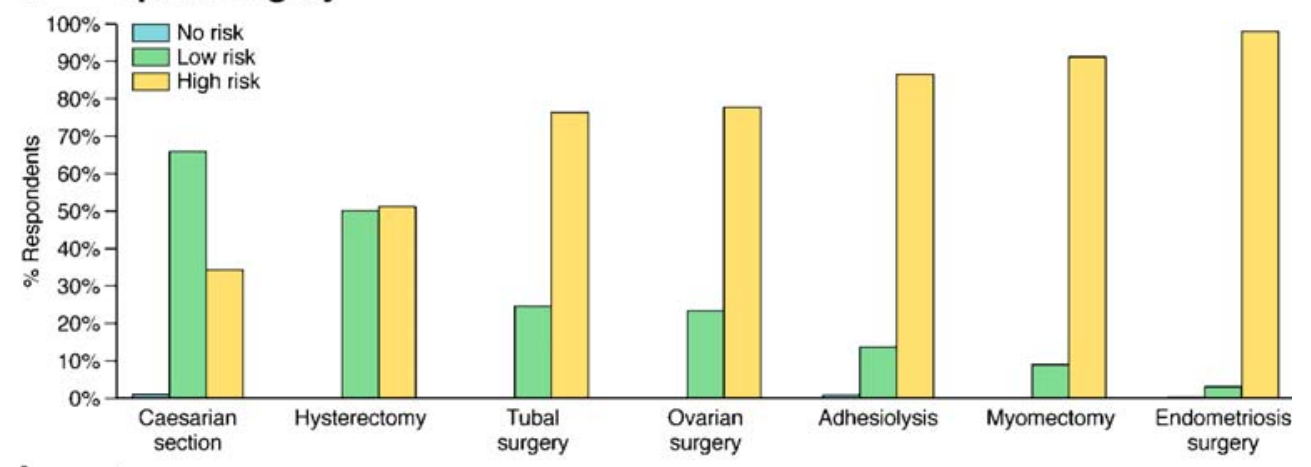

\section{b Laparoscopy}

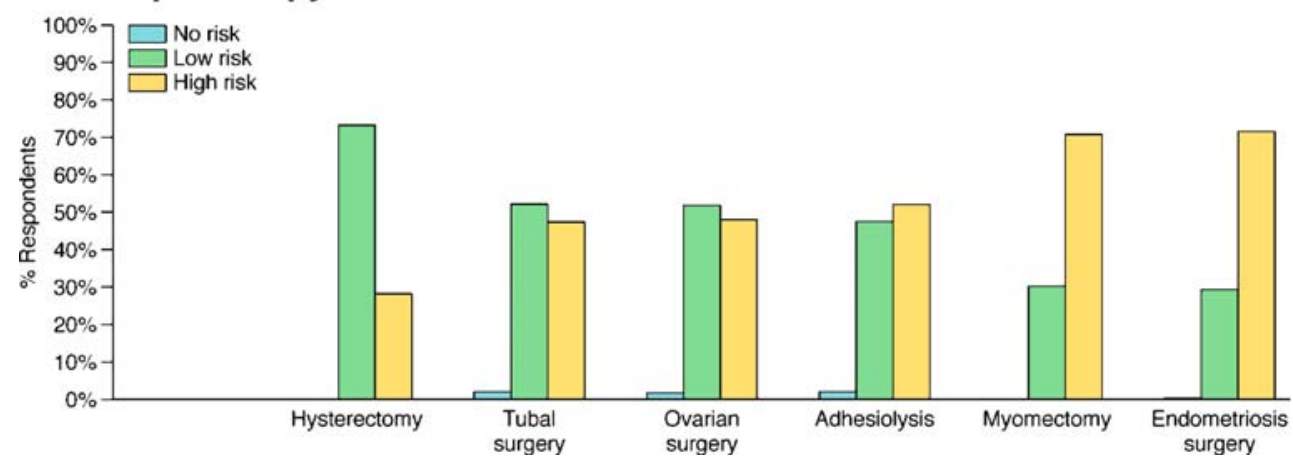

of adhesion formation. Most respondents felt that adhesions have serious consequences, such as small bowel obstruction (SBO), fertility problems, pelvic pain and re-operative complications (Fig. 1).

Considering whether adhesions only develop after open surgery, the majority disagreed $(43.5 \%)$ or strongly disagreed $(37.0 \%)$ but a proportion agreed $(14.3 \%)$ or strongly agreed $(4.9 \%)$ with this statement; $46.9 \%$ strongly disagreed and $42.5 \%$ disagreed that adhesions only formed after laparoscopic surgery, but almost one in ten agreed $(8.2 \%)$ or strongly agreed $(1.7 \%)$.

When asked if the risk of adhesion-related complications following gynaecological laparoscopy was similar to that following most open surgical procedures, the majority disagreed $(60.1 \%)$ or strongly disagreed $(17.5 \%)$. Less than one in five agreed $(16.3 \%)$ or strongly agreed $(3.4 \%)$ with a minority having no view (2.8\%). Surgeons were also asked to rate risk of adhesions after key surgical procedures undertaken by open or laparoscopic surgery (Fig. 2a,b).

When asked if they considered adhesions are now the most common complication of abdominal surgery, while the majority agreed (43.5\%) or strongly agreed (10.3\%), a significant proportion disagreed $(30.7 \%)$ or strongly disagreed $(4.6 \%)$ with one in ten $(10.9 \%)$ having no view. Most respondents agreed that awareness and understanding of the problem of adhesions and the associated healthcare burden need to be raised, not only with surgeons, but also with theatre staff, budget holders, nurses, managers and policy makers (Fig. 3).

When asked if patients should be informed of the risk of adhesions, most respondents agreed (49.0\%) or strongly agreed $(24.8 \%)$ this should happen for all gynaecological
Fig. 2 Consequences of adhesions

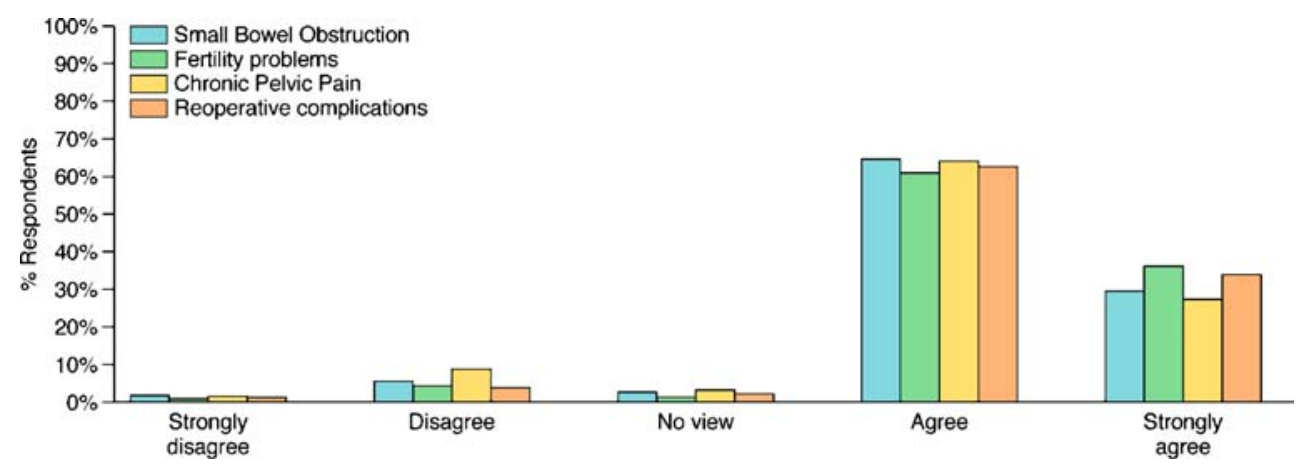


Fig. 3 The importance of raising awareness and understanding amongst healthcare professionals

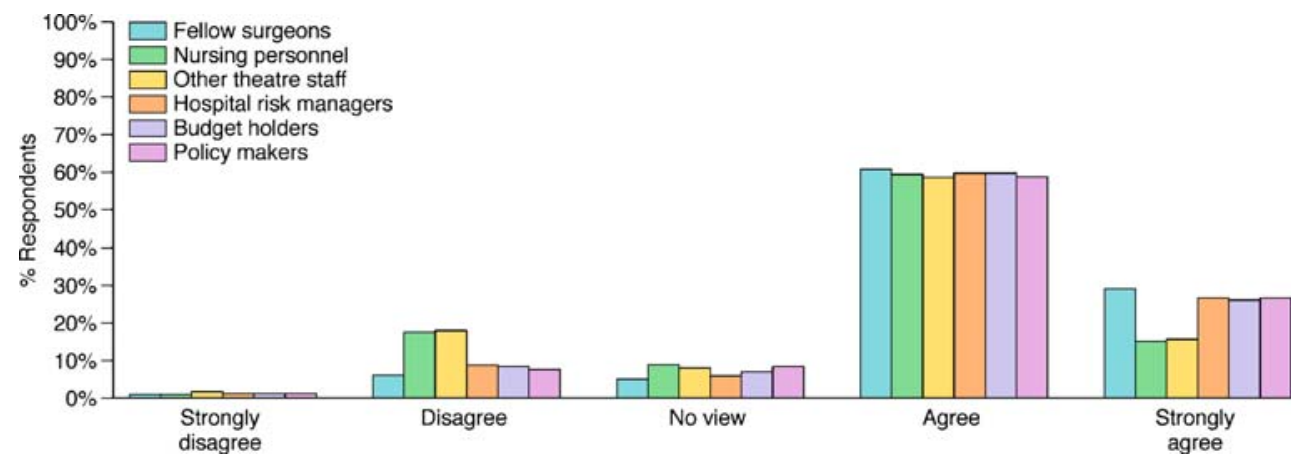

procedures, but over one in five disagreed $(21.0 \%)$ or strongly disagreed $(1.4 \%)$ with $3.7 \%$ having no view. When asked if patients should be informed in high-risk cases only, over half agreed $(35.8 \%)$ or strongly agreed $(17.9 \%)$ with a considerable proportion disagreeing (37.7\%) or strongly disagreeing $(7.4 \%)$ with $1.2 \%$ having no view.

When then asked if they advised patients of the risk of adhesions, $38.4 \%$ of respondents reported they would inform patients routinely for some procedures. Only $22.6 \%$ would routinely inform patients for all procedures and $16.1 \%$ would rarely or just occasionally inform patients of the risks (Fig. 4).

The survey then asked if the surgeon advised the patient of the risks when this was done. The majority claimed they did this either as part of the consent process $(52.6 \%)$ or as part of general information for consent (43.8\%), but $1.9 \%$ claimed they did this after surgery or not at all (1.7\%). When asked how information was provided, the majority claimed they themselves provided the information verbally $(87.5 \%)$ or another team member would discuss it verbally $(0.3 \%)$. Only a minority provided written literature $(2.3 \%)$.

The vast majority agreed or strongly agreed to the statement that surgeons have a duty of care to protect patients by providing the best possible standards of care including steps to reduce adhesion formation (Fig. 5).

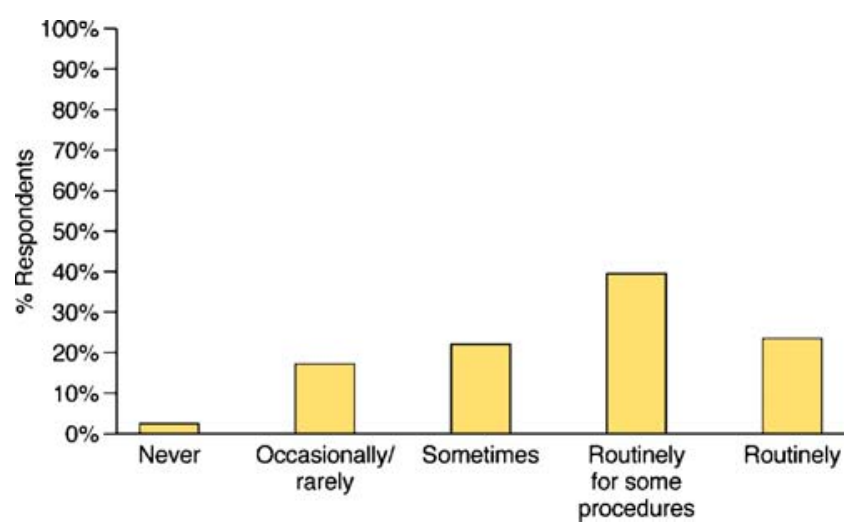

Fig. 4 Advising patients about adhesions
When asked if surgeons should adopt a routine adhesion reduction strategy, 99.4\% agreed or strongly agreed and four out of five surgeons stated that this should be adopted for all gynaecological procedures with most others suggesting this should be adopted in high-risk surgery only. Most respondents considered $(96.9 \%)$ that good surgical technique is fundamental to an adhesion reduction strategy (Fig. 6).

Respondents were asked to rate the importance of key adhesion reduction steps and the responses were then analysed and ranked (Table 2).

When asked if they would consider the use of adhesion reduction agents as part of their adhesion reduction strategy, most felt this was very important following high-risk surgery with fewer considering it important routinely (Table 3).

When asked what were the key factors in choosing an adhesion reduction agent, the respondents rated evidence of safety and efficacy in reducing adhesions as most important (Table 4). Surgeons were also asked to rate their use of the various agents approved for use in Europe (Table 5).

When asked when they would use an adhesion reduction agent, the majority did so only in high-risk surgery (Fig. 7). When asked what best described their current strategy for reducing adhesions, the large majority noted they relied on surgical technique (Fig. 8).

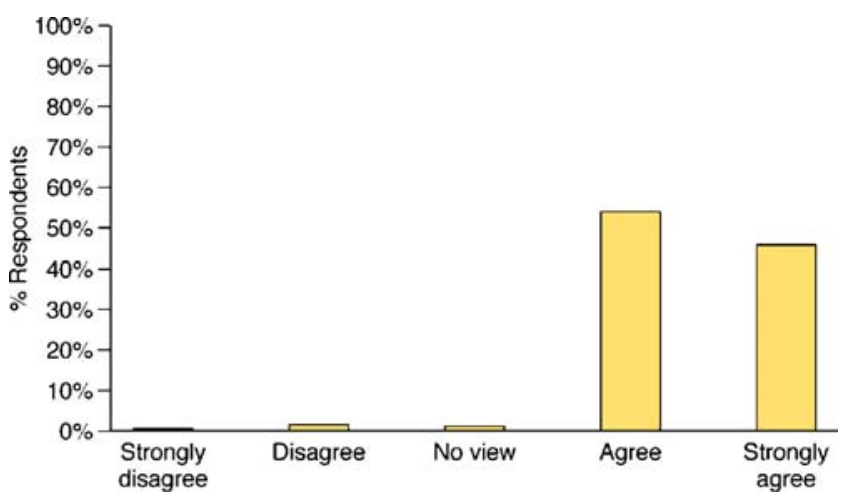

Fig. 5 Do surgeons have a duty of care to reduce adhesions? 


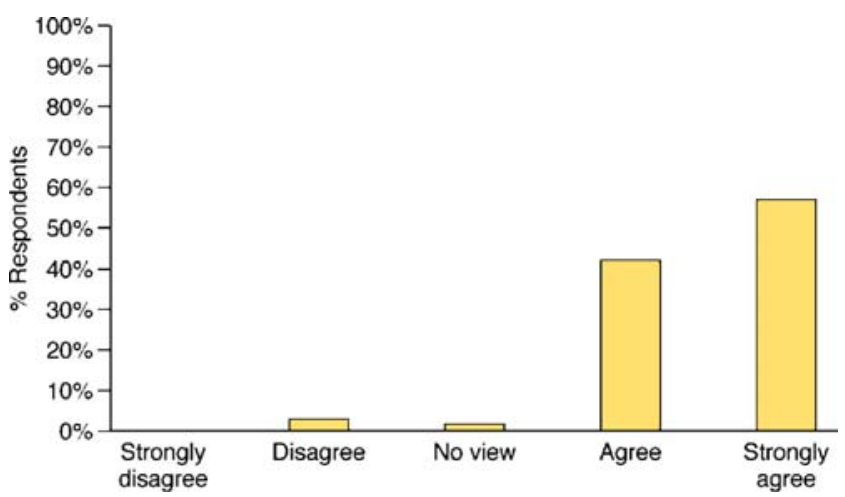

Fig. 6 Is good surgical technique fundamental to an adhesion reduction strategy?

\section{Discussion}

The survey is timely. With the recent publication of the ESGE consensus position on the management of adhesions $[4,5]$, it provides a useful benchmark of current understanding, attitudes and actions of UK gynaecologists.

Surgeon's responses to postal questionnaires are recognised as being low [8-11] and in considering findings a key need is to be confident that any response bias is minimised. Sample bias cannot be excluded from the results. However, our reported overall response rate of $9.7 \%$ (390 of 4,010 mailed) while appearing low is not unexpected and underestimates the true response from the target audience of gynaecological surgeons as the survey was posted to all obstetricians and gynaecologists registered with the UK RCOG since it was not possible to sub-categorise the
RCOG database. The majority of responders were seniorgrade operating gynaecological surgeons representing the key target audience for this survey. We therefore estimate the actual response rate from this audience to be at least $15 \%$. This rate is reflective of surgeon's responses to postal questionnaires [8-11] and higher than we were advised might be expected (personal communication, Gary King, Director GfK HealthCare, GfK NOP Limited). While some tactics recognised to improve postal questionnaire response rates were employed in this survey [12], these did not include follow-up of recipients as this is not viewed favourably by busy surgeons and was not available under the terms of use of the RCOG database. No incentives to complete the survey were employed as these can contravene codes of conduct.

There is also no necessary relation between low response rates and bias [13-15] and any bias in the results of this survey is likely to represent an overestimate of UK gynaecological surgeon's interest, awareness and action on adhesions. This then sets a higher benchmark from which to go forward than may in fact currently be the reality in the broader generalist gynaecological surgical community.

Considering the survey findings, while it is clear that most responding gynaecologists understand that adhesions develop after any kind of gynaecological surgery, around one in seven disagreed or strongly disagreed, although the vast majority considered some procedures carry a higher risk of adhesion formation.

Nearly one in five respondents reported that adhesions only form after open surgery yet important epidemiological

Table 2 Importance of adhesion reduction steps

\begin{tabular}{|c|c|c|c|c|c|}
\hline & Very important $(\%)$ & Important $(\%)$ & Not important $(\%)$ & Avoid (\%) & Do not know $(\%)$ \\
\hline Reduce risk of infection & 66.5 & 33.2 & 0 & 0 & 0.3 \\
\hline Haemostasis & 66.0 & 33.1 & 0.3 & 0 & 0.6 \\
\hline Careful tissue handling & 62.0 & 35.9 & 1.2 & 0 & 0.9 \\
\hline Non-reactive sutures & 32.4 & 61.3 & 4.2 & 0.3 & 1.8 \\
\hline Starch-free gloves (open) & 32.2 & 40.7 & 11.8 & 1.2 & 14.2 \\
\hline Focus on planned surgery & 26.2 & 54.5 & 12.9 & 0.9 & 5.5 \\
\hline Reduce cautery time and frequency & 24.2 & 59.2 & 10.0 & 0 & 6.6 \\
\hline Limit dry towels and sponges & 23.9 & 54.2 & 12.4 & 0.9 & 8.5 \\
\hline Frequent irrigation (laparoscopy) & 21.0 & 51.5 & 13.5 & 0.3 & 13.8 \\
\hline Reduce surgery duration & 20.4 & 56.8 & 12.8 & 0.9 & 9.1 \\
\hline Limit heat & 18.6 & 50.9 & 13.2 & 0.6 & 16.8 \\
\hline Limit use of materials with loose fibres & 17.9 & 63.2 & 7.3 & 1.5 & 10.0 \\
\hline Frequent irrigation (open) & 16.7 & 48.2 & 20.5 & 0.3 & 14.3 \\
\hline Excise tissue-reduce fulguration & 15.4 & 60.9 & 10.8 & 0.3 & 12.6 \\
\hline Magnification-field enhancement & 15.2 & 46.0 & 26.2 & 0.6 & 11.9 \\
\hline Limit suturing & 12.1 & 61.3 & 18.1 & 0.6 & 7.9 \\
\hline Aspirate aerosolised tissue after cautery & 4.0 & 31.1 & 20.0 & 0.6 & 44.3 \\
\hline Latex-free gloves (open) & 3.9 & 13.7 & 53.7 & 0.9 & 27.8 \\
\hline Limit light & 3.6 & 14.2 & 46.2 & 6.5 & 29.6 \\
\hline Reduce pressure and duration of pneumoperitoneum & 3.0 & 14.0 & 48.7 & 1.8 & 32.5 \\
\hline
\end{tabular}


Table 3 Use of adhesion reduction agents as part of an adhesion reduction strategy

\begin{tabular}{lccccc}
\hline & Very important (\%) & Important (\%) & Not important (\%) & Avoid (\%) & Do not know (\%) \\
\hline During all abdominopelvic surgery & 16.5 & 48.4 & 24.5 & 0.9 & 9.7 \\
In high-risk procedures & 52.6 & 40.8 & 3.0 & 0.3 & 3.3 \\
\hline
\end{tabular}

research has shown that the risk of adhesion-related readmission following most gynaecological laparoscopy procedures is comparable to that of gynaecological laparotomy [16]. Although laparoscopic surgery is generally considered to be accompanied by reduced de novo adhesion formation in comparison to laparotomy [17-19], a metaanalysis revealed comparable results for both formation of de novo adhesions and re-formation following laparoscopic and open adhesiolysis [20]. The reasons for this similarity are not fully understood but it is considered that the environment of the pneumoperitoneum [21] and the surgeon's training play an important role [22].

Considering the procedural risk of adhesions, the survey illustrated that, while gynaecological surgeons may be generally aware of adhesions and their consequences, their knowledge is not comprehensive. Most respondents recognised the adhesiogenic nature of undertaking surgery in patients with endometriosis where there is a heightened inflammatory response and angiogenesis [23]. The risk of adhesions following open myomectomy was also recognised, but $30 \%$ considered laparoscopic myomectomy was low risk. While the risk of adhesions may be slightly lower in laparoscopic myomectomy ( $48 \%$ ) than open myomectomy $(\sim 70 \%)[24]$, these procedures are still problematic for patients wishing to become pregnant. While respondents understood the risk of adhesion formation after open adhesiolysis, almost half of respondents considered laparoscopic adhesiolysis was a low-risk procedure, yet research has clearly demonstrated a mean adhesion re-formation rate of $85 \%$ following surgery regardless of the method of adhesiolysis [1]. Patients undergoing open tubal and ovarian surgery have been shown to be at most risk of adhesion-related re-admissions [25], yet almost one in four of the survey respondents considered open tubal and ovarian surgery to be low risk and over half of respondents considered laparoscopic surgery low risk. Whilst these results may reflect some surgeons interpreting tubal surgery as simple sterilisation procedures with a low risk of adhesions, all other tubal and ovarian procedures carry a significant risk of adhesion-related re-admissions [16]. Half of respondents felt that open hysterectomy was a low-risk procedure whereas a recent 7-year audit of admissions for SBO showed that, in non-oncological cases, $50 \%$ of admissions were the result of previous gynaecological surgery with total abdominal hysterectomy cited as the most common cause of SBO [26].

The majority of respondents felt there is a need to encourage heightened awareness and understanding of the problems of adhesions and the associated healthcare burden with theatre staff, budget holders, nurses, managers and policy makers as well as other surgeons. This is indeed one of the key recommendations of the recent ESGE consensus position $[4,5]$ which seeks to ensure adhesions are seen not simply as a technical surgical problem but as an important surgical risk that affects the health of patients and hence, cumulatively, the economics of the entire community.

The survey questioned whether UK gynaecologists felt patients should now be informed of adhesion risks. While the majority of respondents agreed this should occur for all gynaecological procedures, over one in five disagreed. The majority also recognised that surgeons have a duty of care to protect patients by providing the best possible standards of care-including taking steps to reduce adhesions. The established duty of care requires that the clinician must give advice and sufficient information upon which a patient can reach a rational decision as to whether they accept or refuse

Table 4 Key attributes in selecting an anti-adhesion agent

\begin{tabular}{|c|c|c|c|c|c|}
\hline & Very important $(\%)$ & Important $(\%)$ & Not important (\%) & Avoid (\%) & Do not know (\%) \\
\hline Evidence it reduces adhesions & 67.1 & 27.0 & 5.0 & 0.3 & 0.6 \\
\hline Evidence of safety & 63.3 & 27.2 & 8.3 & 0.3 & 0.9 \\
\hline Cost & 29.7 & 29.7 & 33.6 & 5.1 & 1.8 \\
\hline Ease of use & 28.4 & 44.9 & 24.9 & 0.6 & 1.2 \\
\hline \multicolumn{6}{|l|}{ Evidence it impacts on adhesion-related outcomes } \\
\hline Reduces SBO & 30.6 & 42.6 & 19.5 & 1.2 & 6.0 \\
\hline Reduces pelvic pain & 28.1 & 44.6 & 21.3 & 2.7 & 3.3 \\
\hline Improves pregnancy rates & 26.3 & 42.4 & 24.8 & 2.4 & 4.2 \\
\hline No specialist equipment or technique required & 22.8 & 41.0 & 29.6 & 4.8 & 1.8 \\
\hline
\end{tabular}


Table 5 Use of approved anti-adhesion agents

\begin{tabular}{|c|c|c|c|c|c|}
\hline & Use regularly (\%) & Still use occasionally (\%) & Have used in past $(\%)$ & Never used (\%) & Other $(\%)$ \\
\hline $\operatorname{Adept}^{\circledR}(n=346)$ & 47.0 & 29.0 & 14.7 & 9.0 & 0.3 \\
\hline Interceed $^{\circledR}(n=321)$ & 4.2 & 10.3 & 32.3 & 52.9 & 0.3 \\
\hline Seprafilm ${ }^{\circledR}(n=297)$ & 0.7 & 3.0 & 10.5 & 84.7 & 1.0 \\
\hline SurgiWrap $^{\circledR}(n=299)$ & 0.7 & 4.5 & 5.5 & 88.6 & 0.7 \\
\hline Oxiplex $^{\circledR}(n=293)$ & 0.4 & 0.7 & 1.8 & 96.5 & 0.7 \\
\hline SprayGel $^{\circledR}(n=296)$ & 0.3 & 1.0 & 7.3 & 90.6 & 0.7 \\
\hline Hyalobarrier $^{\circledR}(n=296)$ & 0.3 & 0.0 & 3.1 & 95.8 & 0.7 \\
\hline Preclude $^{\circledR}(n=296)$ & 0.0 & 0.0 & 1.0 & 98.3 & 0.7 \\
\hline Other comments $(n=64)$ & 14.5 & 8.1 & 4.8 & 62.9 & 9.7 \\
\hline
\end{tabular}

treatment. In the consent process, it is recommended that patients should be advised of the reasons for and nature of the procedure, the benefits, risks, discomforts and alternatives and the consequences of not undergoing the procedure. Importantly, in the UK, the National Health Service Litigation Authority (NHSLA) has identified a risk level of $1-2 \%$ as being the limit above which failure of notification could be deemed to be negligent [27]. It is common practice in the consent process to advise patients of risks of complications such as general anaesthesia and general complications after laparoscopic surgery, (e.g. pain, bleeding, infection, damage to the bowel-bladder-urethra), but their risk ratios are less [28] than those for a directly adhesion-related re-admission (adhesiolysis) in the first year after open or laparoscopic gynaecological surgery [16].

Although around $60 \%$ of respondents claimed to routinely advise patients of the risk for all or at least some procedures, over $21 \%$ only sometimes advise of the risks and a worrying $16 \%$ would only rarely or just occasionally inform patients. Alarmingly, a minority (1.6\%) claimed they would never inform patients of the risks. This is against the current advice of the NHSLA [27]. Many patients will use the Internet to find out information about the procedure they are to undergo. If they then experience adhesion-related complications, they may seek legal advice

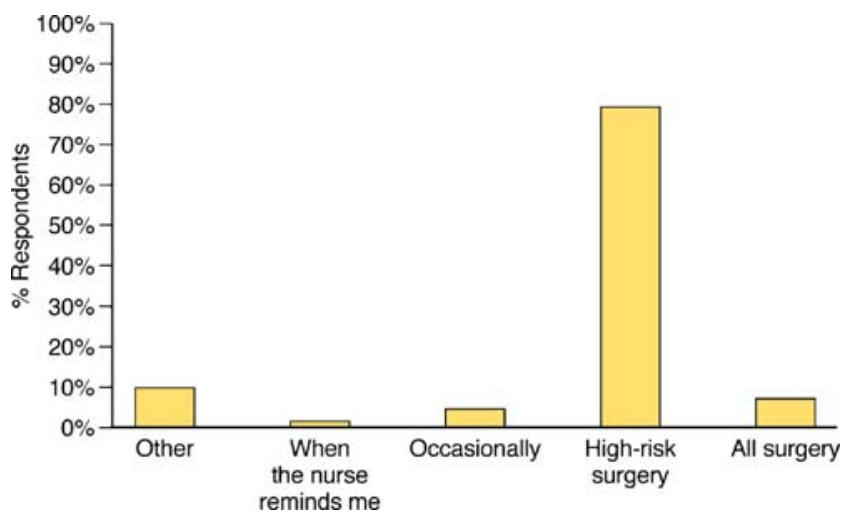

Fig. 7 Use of anti-adhesion agents and if they have not been warned about the risks then there is more likely to be a problem.

The survey also identified that where respondents do advise of the risks of adhesions the overwhelming majority do so as part of the consent process-but $2 \%$ do it after surgery! Moreover, the vast majority provide information verbally. This may be problematic as, unless this is documented clearly in the patient's notes, there is no evidence in a future legal case. The use of written literature should be considered. In our experience, written materials supplement discussion of adhesion risk alongside other surgical complications, and the reaction of the vast majority of patients is very positive. They are pleased that we are thinking about their future, not only the surgery, but are seeing them from a more holistic perspective.

Most respondents agreed that part of the duty of care included taking steps to reduce adhesions and when asked if they would adopt a routine adhesion reduction strategy most agreed that they would. Almost all respondents suggested that this approach should be adopted in all gynaecological surgery, while one in five felt that this should be reserved for high-risk surgery only.

Good surgical technique was agreed by the majority to be fundamental to an adhesion reduction strategy but when

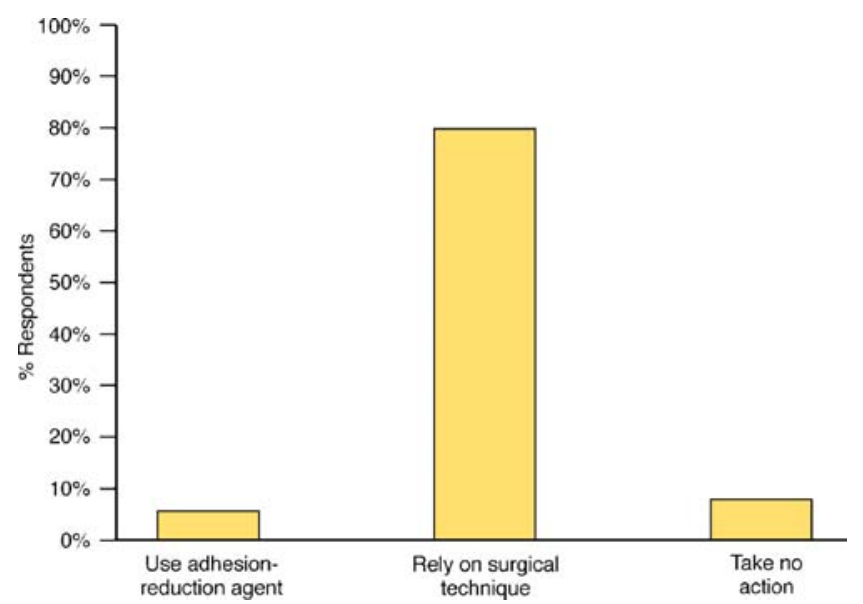

Fig. 8 Current strategy for reducing adhesions 
their understanding of what this constituted was questioned some interesting findings emerged. The key steps of reducing infection risk, good haemostasis and careful tissue handling were all well recognised as important along with other fundamental surgical steps. However, responses to some other important factors gave concerns. Irrigation during laparoscopy was not considered important by $13 \%$ and one in five did not consider it important in open surgery, yet frequent irrigation and aspiration remove most of the contaminants during the surgical procedure, resulting in less damage to the tissues and also ensure that the tissues are protected from desiccation. Emerging data suggest this is particularly beneficial during laparoscopy as the pneumoperitoneum can damage the peritoneum [29-31]. Moreover, just under half of all respondents considered that reducing the pressure and duration of the pneumoperitoneum was important with one third claiming they 'do not know' this is important, yet this is a key area of discussion and one where there is active research [30,31].

When asked if adhesion reduction agents should be used as part of an adhesion reduction strategy, while the majority agreed they should in high-risk surgery, almost $25 \%$ did not consider this important in all abdominopelvic surgery. As it is impossible to identify which patients will be at risk of adhesion-related complications, prevention strategies should be aimed at all patients.

Considering the factors in selecting an anti-adhesion agent, evidence that an agent reduces adhesions and was safe were cited as key. Cost, while important for most, was not felt important by over one third of respondents, yet appears to be a key barrier to many hospitals allowing an agent to be purchased for use. Evidence of impact on adhesion-related outcomes was also considered important. There are however very few studies that have looked at the impact of an agent on clinical outcomes such as pregnancy, reduction in SBO or ease of re-operative surgery, largely because of the complexity of undertaking clinical outcome studies in surgery [32]. Regulatory authorities require studies of adhesion reduction agents for regulatory approval to focus on adhesion reduction [33] and clinical outcome studies are likely to remain beyond their scope.

The current survey directly asked surgeons to rate their use of specific anti-adhesion agents approved for use in Europe. This highlighted that most agents have never been used by respondents and while Interceed ${ }^{\circledR}$ had been well used in the past, it had been superseded in the experience of the majority by Adept ${ }^{\circledR}$. Whether this relates to the move from open to laparoscopic gynaecological surgery where a fluid is simple to use is not identified from the survey, but the recent publication of the pivotal study to assess efficacy and safety may have been influential [34].

What the survey shows, however, is that while Adept ${ }^{\circledR}$ may be the current agent of choice amongst survey respondents, when asked what best describes their current strategy for reducing adhesions, almost $80 \%$ rely on their surgical technique.

Sound epidemiological studies have shown that even with advances in surgical practice, adhesions continue to represent a significant burden for patients, surgeons and healthcare systems $[16,25,35-37]$. Evidence is also increasing to support the efficacy of adhesion reduction agents to complement good surgical practice [5]. Despite this, most survey respondents still rely on surgery alone.

\section{Conclusions}

Notwithstanding the response rate, the survey indicates that amongst what were largely senior-level gynaecological surgeons, there is a general increased awareness of the risk and seriousness of adhesions. However, gynaecological surgeons are not yet routinely advising patients of the risk of adhesions as part of the consent process. Despite evidence indicating that changes in surgical practice have had little impact on reducing adhesion complications, most surgeons responding currently rely on surgery alone as their anti-adhesion strategy. With increasing evidence supporting the efficacy of adhesion reduction agents to complement good surgical practice, as the recent ESGE consensus position on adhesion management proposes, it is timely for all gynaecological surgeons to act on adhesions. This survey of UK gynaecological surgeons provides a useful benchmark for future action on adhesions and similar studies in other countries may be useful to allow for subsequent audit of the recent ESGE consensus proposals for action on adhesions $[4,5]$.

Acknowledgements The survey project and manuscript development was facilitated by Corvus Communications under the direction of the authors. Special thanks for the work of Alison Crowe, Alastair Knight and Jill Kirkdale in patiently supporting and encouraging all of us to actively contribute and feedback on all stages of the project development.

All authors were involved in the design of this research project and the survey questionnaire. All authors reviewed and commented on analysis of data and had considerable input to the development of this manuscript in both writing and review.

The project received funding through an unconditional grant from Baxter BioSurgery.

All authors have been involved in research in adhesions and their management and provided consultancy advice to various commercial companies and participated at various meetings and congresses for which they have received support for their time and expenses. In the context of the work presented here, there is no conflict of interest.

Ethical standards This was a survey on surgeons' attitudes and awareness. The project and survey questionnaire were reviewed and approved by the Council of the Royal College of Obstetricians and Gynaecologists in the UK. All respondents' feedback was analysed anonymously. 
Appendix

\section{Surgical Adhesions Awareness: UK Survey}

This survey, which examines surgeons' current views on the prevention of postoperative adhesions, is being undertaken as a collaborative project. It has been sent to all gynaecologists registered with the Royal College of Obstetrics and Gynaecology. Please take a few minutes to complete the questionnaire. Your feed back will be important in informing on current understanding, attitudes and practices of gynaecological surgeons in the UK.

Findings of the survey will be reviewed on July 5th during the forthcoming British Intemational Congress on Obstetrics and Gynaecology in London (www.bcog2007.co.uk) and will be published following the meeting. The work is part of a broader pan-European project with the Expert Achesions Working Party of the European Society of Gynaecological Endoscopy and will be reviewed in September at their annual congress.

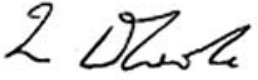

lan Cooke, Emeritus Professor of Obstetrics and Gynaecology, Sheffield

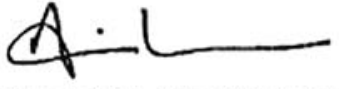

Adrian Lower, Consultant Gynaecologist, London

$$
\text { 1st }
$$

$$
\text { Fuda Mruench }
$$

Enda McVeigh, Consultant Obstetrician and Gynaecologist, Oxford

$$
\text { Cw/fort? }
$$

Geoffrey Trew, Consultant in Reproductive Medicine and Surgery, London

Thank you for taking time to complete and return the survey. Please return the completed survey by folding along the lines indicated and sealing with tape/glue. No stamp is required.

The data will be analysed anonymously, but if you would like us to send you a copy of the results, please provide your contact information below. Also, if you are interested in receiving further information and/or participating at the BICOG session, please tick the box $\square$ and provide your contact details below.

Name:

Postal address:

Postal code:

Email:

1. What specialty (ies) best describes you (tick as appropriate)?

General gynaecological surgeon

Reproductive surgeon

Gynaecological laparoscopist

Other

please describe:

2. What grade best describes your position (tick as appropriate)?

Consultant

Specialist registrar

Trainee

Other

please describe:

3. What NHS Trust do you work for? 
4. Please review the following statements and tick the box that best indicates your level of agreement/disagreement with each statement:

\begin{tabular}{|c|c|c|c|c|c|}
\hline Statement & $\begin{array}{l}\text { Strongly } \\
\text { agree }\end{array}$ & Agree & Disagree & $\begin{array}{l}\text { Strongly } \\
\text { dis agree }\end{array}$ & No view \\
\hline \multicolumn{6}{|l|}{$\begin{array}{l}\text { A. Adhesions develop following any type of } \\
\text { gunaecolo, ical surgery }\end{array}$} \\
\hline \multicolumn{6}{|l|}{ - Only after open surgery } \\
\hline \multicolumn{6}{|l|}{ - Only after laparoscopic surgery } \\
\hline \multicolumn{6}{|l|}{ - Some procedures carry a higher risk } \\
\hline \multicolumn{6}{|c|}{$\begin{array}{l}\text { B. The risk of adhesion-related complications following } \\
\text { gynaecological laparoscopy is similar to that of } \\
\text { most open procedures }\end{array}$} \\
\hline \multicolumn{6}{|l|}{ C. Adhesions have serious consequences in terms of: } \\
\hline \multicolumn{6}{|l|}{ - Smal bowel obstruction } \\
\hline \multicolumn{6}{|l|}{ - Fertility problems } \\
\hline \multicolumn{6}{|l|}{ - Chronic pelvic pain } \\
\hline \multicolumn{6}{|l|}{ - Reoperative complications } \\
\hline \multicolumn{6}{|l|}{$\begin{array}{l}\text { D. Adhesions are now the most common complication } \\
\text { of abdominal surgery }\end{array}$} \\
\hline \multicolumn{6}{|l|}{$\begin{array}{l}\text { E. Awareness/understanding of the problem of } \\
\text { adhesions and the associated healthcare burden } \\
\text { and costs need to be raised among: }\end{array}$} \\
\hline \multicolumn{6}{|l|}{ - Fellow surgeons } \\
\hline \multicolumn{6}{|l|}{ - Nursing personnel } \\
\hline \multicolumn{6}{|l|}{ - Oner theatre stafl } \\
\hline \multicolumn{6}{|l|}{ - Hospital risk managers } \\
\hline \multicolumn{6}{|l|}{ - Budget holders } \\
\hline \multicolumn{6}{|l|}{ - Policy makers } \\
\hline \multicolumn{6}{|l|}{ F. Patients should be informed of the risk of adhesions: } \\
\hline \multicolumn{6}{|l|}{ - In all gynaecological surgical procedures } \\
\hline \multicolumn{6}{|l|}{ - In certain high-risk cases only } \\
\hline \multicolumn{6}{|c|}{$\begin{array}{l}\text { G. Surgeons have a duty of care to protect patients } \\
\text { by providing the best possible standards of care - } \\
\text { including taking steps to reduce adhesion formation }\end{array}$} \\
\hline \multicolumn{6}{|l|}{ H. Surgeons should adopta routine adhesionreduction strategy: } \\
\hline \multicolumn{6}{|l|}{- In all surgery } \\
\hline \multicolumn{6}{|l|}{ - In surgery known $b$ be at higher risk } \\
\hline $\begin{array}{l}\text { 1. Good surgical technique is fundamental to an } \\
\text { adhesion-reduction strategy }\end{array}$ & & & & & \\
\hline
\end{tabular}

5. Please indicate the risk of adhesion formation after each of the following procedures (tick box):

\begin{tabular}{|l|l|l|l|l|l|l|}
\hline \multicolumn{2}{c|}{} & \multicolumn{3}{c|}{ Laparotomy } & \multicolumn{2}{c|}{ Laparoscopy } \\
\hline & High risk & Low risk & No risk & High risk & Low risk & No risk \\
\hline A. Ovarian surgery & & & & & & \\
\hline B. Endometriosis sumery & & & & & & \\
\hline C. Tubal surgery & & & & & & \\
\hline D. Myomectomy & & & & & & \\
\hline E. Adhesiolysis & & & & & & \\
\hline F. Caesarean section & & & & & & \\
\hline G. Hysterectomy & & & & & & \\
\hline
\end{tabular}


6. Please rate the importance of the following as part of an adhesion-reduction strategy (tick box):

\begin{tabular}{|l|l|l|l|l|l|}
\hline & $\begin{array}{l}\text { Very } \\
\text { important }\end{array}$ & Important & $\begin{array}{l}\text { Not } \\
\text { important }\end{array}$ & $\begin{array}{l}\text { To be } \\
\text { avoided }\end{array}$ & $\begin{array}{l}\text { Don't } \\
\text { know }\end{array}$ \\
\hline A. Focus on planned surgery & & & & & \\
\hline B. Excise tissue - reduce fulguration & & & & & \\
\hline C. Careful tissue handling & & & & & \\
\hline D. Magnification/field enhancement techniques & & & & & \\
\hline E. Haemostasis & & & & & \\
\hline F. Reduce cautery time and frequency & & & & & \\
\hline G. Reduce risk of infection & & & & & \\
\hline H. Freque nt irrigation: - In laparotomy & & & & & \\
\hline & & & & & \\
\hline I. Limit heat & & & & & \\
\hline J. Limit light & & & & & \\
\hline $\begin{array}{l}\text { K. Reduce pressure and duration of pneumo- } \\
\text { peritoneum in laparoscopic surgery }\end{array}$ & & & & & \\
\hline L. Aspirate aerosolised tissue following cautery & & & & & \\
\hline $\begin{array}{l}\text { M. Limit s uturing } \\
\text { N. Limit use of materials with loose fibres }\end{array}$ & & & & & \\
\hline O. Limit use of dry towels and sponges & & & & & \\
\hline P. Use of non-reactive sutures & & & & & \\
\hline Q. Use of starch-free gloves in laparotomy & & & & & \\
\hline R. Use of latex-free gloves in laparotomy & & & & & \\
\hline S. Reduce duration of surgery & & & & & \\
\hline $\begin{array}{l}\text { T. Surgeons should consider the use of adhesion- } \\
\text { reduction agents as part of their adhesion- } \\
\text { reduction strategy: }\end{array}$ & & & & & \\
\hline - During all abdominopelvic surgery & & & & \\
\hline
\end{tabular}

7. Key factors in choosing an adhesion-reduction agent include (tick box):

\begin{tabular}{|l|l|l|l|l|l|}
\hline & Essential & $\begin{array}{l}\text { Very } \\
\text { important }\end{array}$ & Important & $\begin{array}{l}\text { Not } \\
\text { important }\end{array}$ & $\begin{array}{l}\text { Don't } \\
\text { know }\end{array}$ \\
\hline A. Cost & & & & & \\
\hline B. Ease of use & & & & & \\
\hline C. No spe cialist equipment or technique required & & & & & \\
\hline D. Evidence of safety & & & & & \\
\hline E. Evidence it reduces adhesions & & & & & \\
\hline $\begin{array}{l}\text { F. Evidence it impacts on adhesion-related outcomes: } \\
\text { - Reduces SBO }\end{array}$ & & & & & \\
\hline - Improves pregnancy rates & & & & & \\
\hline - Reduces pelvic pain & & & & & \\
\hline
\end{tabular}

8. For the following agents approved for use in Europe, please rate your use (if any) of each:

\begin{tabular}{|l|l|l|l|l|l|}
\hline & $\begin{array}{l}\text { Use } \\
\text { regularly }\end{array}$ & $\begin{array}{l}\text { Still use } \\
\text { occasionally }\end{array}$ & $\begin{array}{l}\text { tave used } \\
\text { in past }\end{array}$ & $\begin{array}{l}\text { Never } \\
\text { used }\end{array}$ & $\begin{array}{l}\text { Other - } \\
\text { please describe }\end{array}$ \\
\hline A. Preclude & & & & & \\
\hline B. Interceed & & & & & \\
\hline C. Seprafilm & & & & & \\
\hline D. SprayGel & & & & & \\
\hline E. Hyalobarrier & & & & & \\
\hline F. SurgiWrap & & & & & \\
\hline G. Oxiplex & & & & & \\
\hline H. Adept & & & & & \\
\hline I. Other - please describe & & & & & \\
\hline
\end{tabular}


9. Without checking on your earlier responses, please consider the following statements as they relate to your own practice and tick the appropriate response(s):

A. Do you advise patients of the risk of adhesions?

Routinely before all surgery

Routinely before some procedures

Sometimes before some procedures

(stale which)

On occasion, but rately

(state which)

Never

B. If you advise patients of the risk of adhesions, when do you do this?

Pat of formal consent process

When providing general information before surgery

After surgery

Never

C. If you provide information on adhesions to your patients, how do you do th is?

1 discuss verbally

I provide written literature

Other team member discusses

Other team member provides written fiterature

Other

(state who)

(state who)

(stale how)

D. What best describes your current strategy for reducing adhesions? I take no steps to reduce adhesions

I rely on my surgical technique as the mainstay of my strategy

1 use an adhesion-reduction agent:

E. If you use an adhesion-reduction agent, do you use it in:

All surgery

In high-risk surgery

Occasionally when I remember

Only when the nurses remind me

Other

Thank you for your time in completing the survey. Please fold along the dotted lines, seal and post. Project supported by an unconditional edu cational grant from Baxter BioSurgery

Freepost RRKB-AHCA-ZBXC

Cynaecological Adhesions Survey

PO Box 155

UCKFIELD

TN22 4UA 


\section{References}

1. Diamond MP, Freeman ML (2001) Clinical implications of postsurgical adhesions. Hum Reprod Update 7:567-576

2. Trew G, Lower A (2004) Consensus in adhesion reduction management. The Obstetrician and Gynaecologist 6:1-16

3. Rimbach S, Korell M, Tinneberg HR, DeWilde RL (2004) Adhesions and their prevention in gynaecologic surgery: current status and consensus based on four workshops. Geburtsh Frauenheilk 64:891-899

4. DeWilde RL, Trew G, on behalf of the Expert Adhesions Working Party of the European Society of Gynaecological Endoscopy (ESGE) (2007) Postoperative abdominal adhesions and their prevention in gynaecological surgery. Expert consensus position. Gynecol Surg 4:161-168

5. DeWilde RL, Trew G, on behalf of the Expert Adhesions Working Party of the European Society of Gynaecological Endoscopy (ESGE) (2007) Postoperative abdominal adhesions and their prevention in gynaecological surgery. Expert consensus position. Part 2-steps to reduce adhesions. Gynecol Surg 4:243-253

6. Cooke I (2003) European opinions on postoperative adhesions: survey results. Adhesions News and Views 4:7-9

7. Kelley K, Clark B, Brown V, Sitzia J (2003) Good practice in the conduct and reporting of survey research. Int J Qual Health Care 15:261-266

8. Bhandari M, Devereaux PJ, Swiontkowski MF, Schemitsch EH, Shankardass K et al (2003) A randomized trial of opinion leader endorsement in a survey of orthopaedic surgeons: effect on primary response rates. Int J Epidemiol 32:634-636

9. Matarasso A, Elkwood A, Rankin M, Elkowitz M (2000) National plastic surgery survey: face lift techniques and complications. Plast Reconstr Surg 106:1185-1195

10. Almeida OD Jr (2000) Current state of office laparoscopy surgery. J Am Assoc Gynecol Laparosc 7:545-546

11. Khalily C, Behnke S, Seligson D (2000) Treatment of closed tibia shaft fractures: a survey from 1997 Orthopaedic Trauma Association and Osteosynthesis International-Gerhard Kuntscher Kreis Meeting. J Orthop Trauma 14:577-581

12. Edwards P, Roberts I, Clarke M, DiGuiseppi C, Pratap S et al (2008) Methods to increase response rates to postal questionnaires. Cochrane Database of Systematic Reviews, Issue 2. Art. No.:MR000008. doi:10.1002/14651858.MR000008.pub3

13. Halpern S, Asch DA (2003) Commentary: improving response rates to mailed surveys: what do we learn from randomized controlled trials? Int J Epidemiol 32:637-638

14. Asch DA, Jedrziewski MK, Christakis NA (1997) Response rates to mail surveys published in medical journals. J Clin Epidemiol 50:1129-1136

15. Cummings SM, Savitz LA, Konrad TR (2001) Reported response rates to mailed physician questionnaires. Health Serv Res 35:1347-1355

16. Lower AM, Hawthorn RJS, Clark D, Boyd JH, Finlayson AR et al (2004) Adhesion-related readmissions following gynaecological laparoscopy or laparotomy in Scotland: an epidemiological study of 24046 patients. Hum Reprod 19:1877-1885

17. Operative Laparoscopy Study Group (1991) Postoperative adhesion development after operative laparoscopy: evaluation at early second-look procedures. Fertil Steril 55:700-704

18. Lundorff P, Hahlin M, Källfelt B, Thorburn J, Lindblom B (1991) Adhesion formation after laparoscopic surgery in tubal pregnancy: a randomized trial versus laparotomy. Fertil Steril 55:911-915
19. Nezhat CR, Nezhat FR, Metzger DA, Luciano AA (1990) Adhesion reformation after reproductive surgery by videolaseroscopy. Fertil Steril 53:1008-1011

20. Wiseman DM, Trout JR, Diamond MP (1998) The rates of adhesion development and the effects of crystalloid solutions on adhesion development in pelvic surgery. Fertil Steril 70:702-711

21. Binda MM, Molinas CR, Koninckx PR (2003) Reactive oxygen species and adhesion formation. Clinical implications in adhesion prevention. Hum Reprod 18:2503-2507

22. Luciano A (1984) Laparotomy vs laparoscopy. In: diZerega GS, Malinak LR, Diamond MP, Linsky CB (eds) Treatment of post surgical adhesions, progress in clinical and biological research, vol 358. Wiley-Liss, New York, pp 35-44

23. Canis M, Botchorishvili R, Tamburro S, Safi A, Wattiez A et al (2001) Adhesion prevention in the surgical treatment of pelvic endometriosis. Gynaecological Endoscopy 10:99-106

24. Lau S, Tulandi $T$ (2000) Myomectomy and adhesion formation. In: diZerega GS (ed) Peritoneal surgery. Springer, New York, pp 289-294

25. Lower AM, Hawthorn RJS, Ellis H, The Late O'Brien F, Buchan S, Crowe A (2000) The impact of adhesions on hospital readmissions over ten years after 8489 open gynaecological operations: an assessment from the Surgical and Clinical Adhesions Research Study. Br J Obstet Gynaecol 107:855-862

26. Al-Sunaidi M, Tulandi T (2006) Adhesion-related bowel obstruction after hysterectomy for benign conditions. Obstet Gynecol 108:1162-1166

27. NHS Litigation Authority (2004) Informed consent NHSLA risk alert 2004; 4. http://www.nhsla.com/NR/rdonlyres/AD7A7848E9A3-4668-839F-43E54BBFA3A1/0/RiskManagementAlert4. pdf. Accessed April 2008

28. Trew G (2006) Postoperative adhesions and their prevention. Rev Gynaecol Perinat Pract 6:47-56

29. Molinas CR, Koninckx PR (2000) Hypoxemia induced by $\mathrm{CO}_{2}$ or helium pneumoperitoneum is a co-factor in adhesion formation in rabbits. Hum Reprod 15:1758-1763

30. Binda MM, Molinas CR, Mailova K, Koninckx PR (2004) Effect of temperature upon adhesion formation in a laparoscopic mouse model. Hum Reprod 19:2626-2632

31. Binda MM, Molinas CR, Hansen P, Koninckx PR (2006) Effect of desiccation and temperature during laparoscopy on adhesion formation in mice. Fertil Steril 86:166-175

32. Wilson MS, Menzies D, Knight AD, Crowe AM (2002) Demonstrating the clinical and cost effectiveness of adhesion reduction strategies. Colorectal Dis 4:355-360

33. Guidance for Industry (2002) Guidance for resorbable adhesion barrier devices for use in abdominal and/or pelvic surgery. DHHS/ FDA. http://www.fda.gov/cdrh/ode/guidance/1356.pdf. Accessed February 2008

34. Brown CB, Luciano AA, Martin D, Peers E, Scrimgeour A, diZerega GS, on behalf of the Adept Adhesion Reduction Study Group (2007) Adept (icodextrin 4\% solution) reduces adhesions after laparoscopic surgery for adhesiolysis: a double-blind, randomized, controlled study. Fertil Steril 88:1413-1426

35. Parker MC, Ellis H, Moran BJ, Thompson JN, Wilson MS et al (2001) Postoperative adhesions: ten-year follow-up of 12,584 patients undergoing lower abdominal surgery. Dis Colon Rectum 44:822-830

36. Parker MC, Wilson MS, Menzies D, Sunderland G, Thompson JN et al (2004) Colorectal surgery: the risk and burden of adhesionrelated complications. Colorectal Dis 6:506-511

37. Parker MC, Wilson MS, Menzies D, Sunderland G, Clark DN et al (2005) The SCAR-3 study: 5-year adhesion-related readmission risk following lower abdominal surgical procedures. Colorectal Dis 7:551-558 